\title{
Severe preeclampsia and eclampsia: incidence, complications, and perinatal outcomes at a low-resource setting, Mpilo Central Hospital, Bulawayo, Zimbabwe
}

\author{
This article was published in the following Dove Press journal: \\ International Journal of Women's Health \\ 17 May 2017 \\ Number of times this article has been viewed
}

\author{
Solwayo Ngwenya ${ }^{1-3}$ \\ 'Department of Obstetrics \& \\ Gynaecology, Mpilo Central Hospital, \\ 2Department of Obstetrics \& \\ Gynaecology, Royal Women's Clinic, \\ ${ }^{3}$ National University of Science and \\ Technology, Medical School, Bulawayo, \\ Matabeleland, Zimbabwe
}

Background: Severe preeclampsia is a disorder of pregnancy characterized by high blood pressure and significant proteinuria after 20 weeks gestation. Severe preeclampsia and eclampsia have considerable adverse impacts on maternal, fetal, and neonatal health especially in low-resource countries. Hypertensive disorders of pregnancy are the third leading cause of maternal deaths in Sub-Saharan Africa. Significant avoidable maternal and neonatal morbidity and mortality may result.

Objectives: This study aimed 1) to determine the incidence of severe preeclampsia/eclampsia in a low-resource setting; 2) to determine the maternal complications of severe preeclampsia/ eclampsia in a low-resource setting; 3 ) to determine the perinatal outcomes of severe preeclampsia/eclampsia in a low-resource setting.

Methods: This was a retrospective descriptive cohort study carried out at Mpilo Central Hospital, a tertiary teaching referral government hospital in a low-resource setting in Bulawayo, Zimbabwe. Data were obtained from the birth registers in labor ward, intensive care unit, and neonatal intensive care unit of patients who had a diagnosis of severe preeclampsia or eclampsia for the period January 1, 2016, to December 31, 2016. The case notes were retrieved and the demographic, clinical, and outcome data were gathered.

Results: There were 9,086 deliveries at the institution during the period January 1, 2016, to December 31, 2016. There were 121 cases of severe preeclampsia/eclampsia. The incidence of severe preeclampsia/eclampsia was $1.3 \%$ at Mpilo Central Hospital. The most common major complication was HELLP syndrome (9.1\%). Maternal mortality was $1.7 \%$. There were 127 babies born with six sets of twins, $49.6 \%$ of the babies were lost through stillbirths and early neonatal deaths.

Conclusion: The incidence of severe preeclampsia/eclampsia at Mpilo Central Hospital was $1.3 \%$. The most common maternal complication was hemolysis elevated liver enzymes low platelet syndrome. Maternal mortality was $1.7 \%$ due to acute renal failure. Nearly half $(49.6 \%)$ of the babies born were lost to stillbirths and early neonatal deaths.

Keywords: severe preeclampsia, eclampsia, mortality, morbidity, perinatal outcomes, lowresource settings, Mpilo Central Hospital

\section{Introduction}

Mpilo Central Hospital is located in Bulawayo. Bulawayo is the second largest city in Zimbabwe after the capital city Harare, with a population of 653,337 as of the 2012 census. ${ }^{1}$ It is located in Matabeleland, $439 \mathrm{~km}$ southwest of Harare, on the way to Victoria Falls. 
Severe preeclampsia/eclampsia has grave consequences for both maternal and neonatal health, associated with $50,000-100,000$ annual deaths globally, as well as serious fetal and neonatal morbidity and mortality. ${ }^{2}$ These disorders of pregnancy have a predominance in low- and middle-income countries. ${ }^{3}$ There were an estimated 287,000 maternal deaths worldwide in 2010. The biggest killers of pregnant women being hemorrhage, hypertensive disorders, and sepsis. ${ }^{4}$

Sub-Saharan Africa has the highest maternal mortality ratio at 500 per 100,000 live births. ${ }^{5}$ In Zimbabwe, preeclampsia and eclampsia are the third leading causes of death after AIDS-defining conditions and postpartum hemorrhage. ${ }^{6}$ Hypertensive disorders also indirectly contribute to maternal deaths by being a common risk associated with postpartum hemorrhage. $^{7}$

The incidence of preeclampsia/eclampsia in Zimbabwe has not been documented in the literature before. The incidence in Tanzania, a Sub-Saharan African country, was found to be $1.7 \%{ }^{8}$ and in the United Kingdom, in Europe, it was $0.5 \%{ }^{9}$

\section{Methods}

This was a retrospective descriptive cohort study carried out at Mpilo Central Hospital, a tertiary teaching referral government hospital in a low-resource setting in Bulawayo, Zimbabwe. Data were obtained from the birth registers in labor ward, intensive care unit (ICU), and neonatal intensive care unit (NICU) of patients who had a diagnosis of severe preeclampsia or eclampsia for the period January 1, 2016, to December 31, 2016. Severe preeclampsia was diagnosed in those patients with high blood pressure (diastolic $\geq 110 \mathrm{mmHg}$ ) and either severe headaches, epigastric pain, or deranged biochemical/hematological blood indices. Eclampsia was diagnosed in women who had a grand mal seizure with features of preeclampsia and no previous history of a seizure disorder such as epilepsy. Women with such history were excluded from the study. Early neonatal death was recorded within 7 days of birth.

The case notes were retrieved, and the demographic, clinical, and outcome data were gathered. The SPSS Version 21 (IBM Corp., Armonk, NY, USA) statistical tool was used to calculate the mean and standard deviation (SD) figures. Simple statistical tests were used on absolute numbers to calculate percentages. Chi-square test was used to calculate $P$-values. A $P$-value of $<0.05$ was considered statistically significant.

\section{Ethical approval}

The Ethics Committee of Mpilo Central Hospital approved this study and waived the need for patient consent to review their medical records due to the non-interventional nature of the study, with all data being anonymous.

\section{Results}

There were 9,086 deliveries at the institution during the period January 1, 2016, to December 31, 2016. There were 121 cases of severe preeclampsia/eclampsia. The incidence of severe preeclampsia/eclampsia was 1.3\% at Mpilo Central Hospital. The mean age was 27.7 years $(\mathrm{SD} \pm 7.4)$ and the mean parity was $1.0(\mathrm{SD} \pm 1.0)$ for the studied group of patients. The mean systolic blood pressure was $168(\mathrm{SD} \pm 27)$ and the mean diastolic blood pressure was 113 (SD \pm 18 ). About $81 \%$ of the cases had a proteinuria of $\geq+++$.

Tables 1-4 summarize the results of the study. More than a quarter (26.4\%) of the cases were unbooked. The cases were predominantly of severe preeclampsia $(78.5 \%)$ and $21.5 \%$ were eclamptic. The majority of cases (57.9\%) were of early-onset preeclampsia (EOP) $<34$ weeks gestation; $42.1 \%$ were of late-onset preeclampsia (LOP) $\geq 34$ weeks gestation; $15.7 \%$ of cases were HIV seropositive; $78.5 \%$ of the cases were delivered

Table I Maternal characteristics

\begin{tabular}{|c|c|}
\hline Characteristic & $\mathbf{N}(\%)$ \\
\hline Booked $>4$ ANC visits & $89(73.6)$ \\
\hline Unbooked $<4$ ANC visits & $32(26.4)$ \\
\hline Total & $121(100)$ \\
\hline \multicolumn{2}{|l|}{ Proteinuria } \\
\hline$\geq+++$ & $98(81.0)$ \\
\hline++ & $21(17.3)$ \\
\hline+ & $2(1.7)$ \\
\hline Total & $121(100)$ \\
\hline Severe preeclampsia & $95(78.5)$ \\
\hline Eclampsia & $26(21.5)$ \\
\hline Total & $121(100)$ \\
\hline EOP $<34$ weeks & $55(57.9)$ \\
\hline LOP $\geq 34$ weeks & $40(42.1)$ \\
\hline Total & $95(100)$ \\
\hline HIV +ve & $19(15.7)$ \\
\hline HIV -ve & $89(73.6)$ \\
\hline Unknown status & $13(10.7)$ \\
\hline Total & $121(100)$ \\
\hline Vacuum delivery & $\mathrm{I}(0.8)$ \\
\hline Hystorotomy & $8(6.6)$ \\
\hline NVD & $17(14.1)$ \\
\hline LSCS & $95(78.5)$ \\
\hline Total & $121(100)$ \\
\hline
\end{tabular}


Table 2 Major maternal complications and outcomes

\begin{tabular}{ll}
\hline Characteristic & $\mathbf{N}(\%)$ \\
\hline Major complications & \\
No complication & $103(85.1)$ \\
HELLP syndrome & $11(9.1)$ \\
Abruptio placenta & $3(2.5)$ \\
Acute renal failure & $2(1.7)$ \\
DIC & $1(0.8)$ \\
Pulmonary edema & $1(0.8)$ \\
Total & $121(100)$ \\
Outcomes & \\
Survived & $119(98.3)$ \\
Died & $2(1.7)$ \\
Total & $121(100)$ \\
\hline
\end{tabular}

Abbreviations: HELLP, hemolysis elevated liver enzymes low platelet; DIC, disseminated intravascular coagulation.

by lower segment cesarean section (LSCS); and 6.6\% had a hystorotomy. All the patients received magnesium sulfate chemotherapy for the prevention and treatment of eclamptic seizures. All the cases were admitted to ICU. The most common major maternal complication was HELLP syndrome (9.1\%) and the majority of cases had no major complication (85.1\%). Maternal mortality was $1.7 \%$ from acute renal failure.

There were 127 babies born with six sets of twins during this period of the study among the studied cohort. The mean gestational age was 33.4 weeks gestation $(\mathrm{SD} \pm 4.4)$ and the mean birth weight was $1,906 \mathrm{~g}(\mathrm{SD} \pm 785.8)$ for the studied

Table 3 Perinatal outcomes

\begin{tabular}{ll}
\hline Outcomes & N (\%) \\
\hline Stillbirths & $28(22.0)$ \\
Live births & $99(78.0)$ \\
Total & $127(100)$ \\
NICU admission & \\
No & $45(45.5)$ \\
Yes & $54(54.5)$ \\
Total & $99(100)$ \\
Reason for admission & \\
Low Apgar score & $10(18.5)$ \\
Prematurity/LBW/RDS & $44(81.5)$ \\
Total & $54(100)$ \\
NICU outcomes & \\
Early neonatal deaths & $35(64.8)$ \\
Discharged & $19(35.2)$ \\
Total & $54(100)$ \\
Mortality weights & \\
$500-999 \mathrm{~g}$ & $15(42.9)$ \\
I,000-I,499 g & $16(45.7)$ \\
I,500-I,999 g & $4(I 1.4)$ \\
$2,000-2,499 \mathrm{~g}$ & $0(0)$ \\
Total & $35(100)$ \\
\hline A &
\end{tabular}

Abbreviations: NICU, neonatal intensive unit; LBW, low birth weight; RDS, respiratory distress syndrome.
Table 4 Differences: maternal and fetal/neonatal morbidity and mortality

\begin{tabular}{|c|c|c|c|}
\hline Morbidity/mortality & $\begin{array}{l}\text { Severe } \\
\text { preeclampsia, } \\
\text { n (\%) }\end{array}$ & $\begin{array}{l}\text { Eclampsia, } \\
\text { n (\%) }\end{array}$ & $P$-value \\
\hline \multicolumn{4}{|l|}{ Maternal } \\
\hline $\mathrm{APH}(\mathrm{n}=3)$ & $3(100)$ & $0(0)$ & $<0.05$ \\
\hline $\operatorname{DIC}(n=1)$ & $0(0)$ & $\mathrm{I}(100)$ & $<0.05$ \\
\hline Pulmonary edema $(n=I)$ & $\mathrm{I}(100)$ & $0(0)$ & $<0.05$ \\
\hline Renal failure $(n=2)$ & $I(50)$ & I (50) & NS \\
\hline HELLP syndrome $(n=\mid I)$ & $8(72.7)$ & $3(27.3)$ & NS \\
\hline Death $(n=2)$ & I (50) & I (50) & NS \\
\hline \multicolumn{4}{|l|}{ Fetal/neonatal } \\
\hline Stillbirth $(n=28)$ & $24(85.7)$ & $4(14.3)$ & $<0.05$ \\
\hline Low Apgar score $(n=10)$ & $5(50)$ & $5(50)$ & NS \\
\hline Prematurity/LBW/RDS $(\mathrm{n}=44)$ & $30(68.2)$ & $14(31.8)$ & NS \\
\hline Early neonatal death $(n=35)$ & $20(57.1)$ & 15 (42.9) & NS \\
\hline
\end{tabular}

Abbreviations: APH, antepartum hemorrhage; NS, not significant; LBW, low birth weight; HELLP, hemolysis elevated liver enzymes low platelet; DIC, disseminated intravascular coagulopathy; RDS, respiratory distress syndrome.

group of patients. Approximately $22 \%$ of the babies were stillborn, and $54.5 \%$ of the live babies were admitted to NICU. The vast majority of those admitted (81.5\%) were due to a combination of prematurity, low birth weight, and respiratory distress syndrome (RDS), and 18.5\% were due to low Apgar scores. Out of the total number (127) of babies born, 35 (27.6\%) were early neonatal deaths. Early neonatal mortality was high in those with very low/low birth weight.

Table 4 shows the differences between maternal and fetal/neonatal morbidity and mortality. There was a statistical difference between antepartum hemorrhage in severe preeclampsia and eclampsia $(100 \%$ vs $0 \%, P<0.05)$. There was no statistical difference between the two groups in terms of renal failure, HELLP syndrome, and maternal mortality. There was a statistical difference between the two groups in terms of stillbirths $(85.7 \%$ vs $14.3 \%, P<0.05)$. There was no statistical difference between the two groups in terms of low Apgar scores, prematurity/low birth weight/respiratory distress syndrome, and early neonatal deaths.

\section{Discussion}

This study shows that the incidence of severe preeclampsia/ eclampsia at Mpilo Central Hospital, Bulawayo, Zimbabwe, was $1.3 \%$, which is similar to the one found in Tanzania $(1.7 \%)$. In the UK, it was $0.5 \%$. In low-resource settings, patients fail to book due to financial constraints, and this may lead to poor outcomes.

The HIV prevalence among this cohort was $15.7 \%$ and a significant proportion $(10.7 \%)$ presented to the labor 
ward with an unknown status mainly because more than a quarter of them were unbooked (26.4\%). The prevalence of HIV infection among the obstetric patient in the unit is $16 \%$, and the national figure for Zimbabwe is $15 \%$ among adults $\geq 15$ years. $^{10}$

The patients presented with gross disease, most of the time with proteinuria $(\geq+++)$, mean systolic blood pressure of 168 (SD \pm 27 ), mean diastolic blood pressure of 113 (SD \pm 18$)$, or with eclampsia (21.5\%). These were mostly very sick patients. At this unit, EOP constitutes the majority of cases at $57.9 \%$ while in the developed world EOP represents $10 \%{ }^{11}$ of preeclamptic cases. The predominance of EOP or LOP has huge geographical differences. ${ }^{12}$

Maternal complications of severe preeclampsia/eclampsia can be serious, leading to maternal, fetal, and neonatal morbidity and mortality. These include HELLP syndrome, ${ }^{13,14}$ disseminated intravascular coagulopathy and acute renal failure. Severe preeclampsia was found to be associated with an 8.7-fold risk of composite maternal complication. ${ }^{15}$ The risk of a woman in the developing world dying from a maternal-related cause is 33 times higher than a woman in the developed world. ${ }^{16}$ Maternal mortality results from cerebral hemorrhage, ${ }^{17}$ pulmonary edema, ${ }^{18}$ acute renal failure, hepatic rupture, or DIC. Long-term effects may include chronic renal failure, cardiovascular disease, ${ }^{19}$ or cortical blindness. Most patients $(85.1 \%)$ did not have a major complication. The most common maternal complication was HELLP syndrome at $9.1 \%$ and no patient died from it.

Most of the patients were delivered by cesarean section (78.5\%) due to the seriousness of the condition, and in most cases, there would be delayed presentation; hence no further time would be available to consider vaginal delivery. Despite having $75 \%$ of the patients being booked, factors that contributed to delay in seeking treatment were multifactorial. There was a combination of sudden presentation of the disease, missed diagnosis by poor attenders, patients' own delay to seek treatment due to either taking the condition lightly or lack of money. Approximately $6.6 \%$ of the cases underwent a hystorotomy usually for severe EOP/eclampsia. The cesarean section rate for the unit is $30.7 \%$. All the patients with severe preeclampsia/eclampsia were treated with magnesium sulfate for $24-48$ hours $^{20}$ and were admitted to ICU as per the labor ward protocol for the unit.

Maternal mortality was $1.7 \%$. The two patients who died had acute renal failure, and there was delay in reaching the hospital due to the distance between the referral centre and the hospital. Considering the serious nature of the disease and its complications, and the low-resource setting, maternal mortality seems to be curtailed and $98.3 \%$ survived the disease. The blanket use of magnesium sulfate seems to have good maternal outcomes as most of the very sick patients survived. No maternal deaths were reported in similar studies in rich-resourced countries such as Kuwait ${ }^{21}$ and UK. ${ }^{9}$

Fetal/neonatal complications include stillbirths, iatrogenic prematurity and its complications, and very low/ low birth weight. ${ }^{22}$ About $22 \%$ of the babies were stillborn showing the serious harm that these hypertensive disorders can inflict on fetal health. More than half (54.5\%) of the live babies were admitted to the NICU showing continued strain on neonatal health. Neonatal morbidity is a costly affair in an already low-resourced setting. Early neonatal deaths were caused by severe prematurity, very low/low birth weight, and respiratory distress syndrome. The patients presented late and were very sick, giving no time for interventions such as corticosteroids for fetal lung maturation to be administered. Being born abruptly prematurely, having very low/ low birth weight in a low-resource setting, the odds weigh heavily against the tender, fragile lives of the neonates. It is worrying that nearly half of the babies were lost through stillbirths and early neonatal deaths. This is mainly due to the majority of cases presenting with EOP (57.9\%). In these hypertensive disorders of pregnancy, the babies seem to come out worse off as compared to their mothers. It would be ideal to have outcomes favorable both to the mothers and to their babies.

In low-resource setting, there are few health workers who are not well-trained to recognize and manage serious maternal and fetal complications early enough to prevent poor perinatal outcomes. The health workers are also not well-paid and are not well-motivated. There is also the issue of inadequate equipment/facilities and resources. Ultrasonography, a piece of equipment that would aid in screening for fetal growth, is not widely available. The instrument for fetal heart rate monitoring remains the Pinard stethoscope, which may not be properly used causing missed diagnosis in fetal heart rate abnormalities.

This study is very important in twofolds. First, there is no similar detailed study that exists in the literature that sheds light about the profound serious impacts that severe preeclampsia/eclampsia has on maternal, fetal, and neonatal health in low-resource setting. It is imperative to provide universal antenatal care to pregnant women as a preventative step to educate women about the dangers of severe preeclampsia/eclampsia.

Second, it gives global policy makers an insight into helping tackle one of the major contributors to global maternal and neonatal morbidity and mortality. Tackling such huge 
problems needs global efforts involving brainstormers, field experts, financial institutions, health organizations, governments, and international organizations.

\section{Conclusion}

The incidence of severe preeclampsia/eclampsia at Mpilo Central Hospital was $1.3 \%$. The most common maternal complication was HELLP syndrome, and none of the patients died of it. Maternal mortality was $1.7 \%$ from acute renal failure. The most common fetal/neonatal complications were stillbirths, prematurity, very low/low birth weight, and respiratory distress syndrome. Nearly half $(49.6 \%)$ of the babies were lost through stillbirths and early neonatal deaths.

To tackle these figures on maternal, fetal, and neonatal health, governments in low-resource settings must focus on development and enabling women to be in an economic position to access health care easily. There should be affordable and accessible antenatal care services where women are taught about the dangers of preeclampsia/eclampsia so that they present early to hospitals. This would help prevent complications and unnecessary loss of lives.

Neonatal care facilities need to be improved to improve the outcomes from the units. Neonatal health must be placed on the global agenda and given the same attention as maternal health. Global efforts must involve developmental aid and debt relief to poor countries so that these countries can channel the funds to women's and neonatal health issues.

\section{Disclosure}

The author reports no conflicts of interest in this work.

\section{References}

1. ZIMDAT; Census Report 2012. Available from: www.zimstat.co.zw. Accessed December 1, 2016.

2. Oyston CJ, Stanley JL, Baker PN. Potential targets for the treatment of preeclampsia. Expert Opin Ther Targets. 2015;19(11):1517-1530.

3. Gathiram P, Moodley J. Pre-eclampsia: its pathogenesis and pathophysiology. Cardiovasc J Afr. 2016;27(2):71-78.

4. Say L, Chou D, Gemmill A, et al. Global causes of maternal death: a WHO systematic analysis. Lancet Glob Health. 2014;2:e323-e333.

5. Boene H, Vidler M, Sacoor C, et al. Community perceptions of preeclampsia and eclampsia in southern Mozambique. Reprod Health. 2016;13(Suppl 1):33.
6. Munjanja S. Zimbabwe maternal and perinatal mortality study. Ministry of Health and Child Welfare/Unicef; 2007. Available from: www.unicef.org. Accessed December 1, 2016.

7. Ngwenya S. Postpartum haemorrhage: incidence, risk factors, and outcomes in a low resource setting. Int J Women's Health. 2016;8: 647-650. eCollection 2016.

8. Ajah LO, Ozonu NC, Ezeonu PO, Lawani LO, Obuna JA, Onwe EO. The feto-maternal outcome of preeclampsia with severe features and eclampsia in Abakaliki, South-East Nigeria. J Clin Diagn Res. 2016; 10(9):QC18-QC21.

9. Tuffnell DJ, Jankowicz D, Lindow SW, et al; Yorkshire Obstetric Critical Care Group. Outcomes of severe preeclampsia/eclampsia in Yorkshire 1999/2003. BJOG. 2005;112(7):875-880.

10. ZIMDAT; Zimbabwe Demographic Health Survey Report; 2010/11.

11. Zuberi NF, Arif K, Khan FM, Pal JA. A comparison of severe preeclampsia/eclampsia in patients with and without HELLP syndrome. J Pak Med Assoc. 1998;48(2):29-32.

12. Kinay T, Kucuk C, Kayikcioglu F, Karakaya J. Severe preeclampsia versus HELLP syndrome: maternal and perinatal outcomes at $<34$ and $\geq 34$ weeks' gestation. Balkan Med J. 2015;32(4):359-363.

13. Anath CV, Lavery JA, Friedman AM, Wapner RJ, Wright JD. Serious maternal complications in relation to severe pre-eclampsia: a retrospective cohort study of the impact of hospital volume. BJOG. Epub 2016 Oct 21 .

14. Trends in maternal mortality 1990 to 2015. WHO, UNICEF, UNFPA, World Bank and the United Nations Population Division; Nov 2015 WHO/RHR/15.23. Available from: www.who.int. Accessed December 1, 2016.

15. Ghimire S. Eclampsia: feto-maternal outcomes in a tertiary care centre in Eastern Nepal. JNMA J Nepal Med Assoc. 2016;54(201):24-28.

16. Imarengiaye $\mathrm{CO}$, Isesele $\mathrm{TO}$. Intensive care management and outcome of women of women with hypertensive diseases of pregnancy. Niger Med J. 2015;56(5):333-337.

17. Paauw ND, Luijken K, Franx A, Verhaar MC, Lely AT. Long-term renal and cardiovascular risk after preeclampsia: towards screening and prevention. Clin Sci(Lond). 2016;130(4):239-246.

18. Robillard PY, Dekker G, Iacobelli S, Chaouat G. An essay of reflection: why does preeclampsia exist in humans, and why are there such huge geographical differences in epidemiology? J Reprod Immunol. 2016;114: 44- 47.

19. Iacobelli S, Bonsante F, Robillard PY. Pre-eclampsia and preterm birth in Reunion Island: a 13 years cohort-based study. Comparison with international data. J Matern Fetal Neonatal Med. 2016;29(18): 3035-3040.

20. Duley L, Golmezoglu AM, Chou D. Magnesium sulphate versus lytic cocktail for eclampsia. Cochrane Pregnancy and Childbirth Group. Cochrane Database Syst Rev. 2010;9:CD002960.

21. Chibber R, Al-Hijji J, Amen A, et al. Maternal and perinatal outcome of eclampsia over a decade at a tertiary hospital in Kuwait. J Matern Fetal Neonatal Med. 2016;29(19):3132-3137.

22. Agida ET, Adeka BI, Jibril KA. Pregnancy outcome in eclamptics at the University of Abuja Teaching Hospital, Gwagwalada, Abuja: a 3 year review. Niger J Clin Pract. 2010;13(4):394-398.
International Journal of Women's Health

\section{Publish your work in this journal}

The International Journal of Women's Health is an international, peerreviewed open-access journal publishing original research, reports, editorials, reviews and commentaries on all aspects of women's healthcare including gynecology, obstetrics, and breast cancer. The manuscript management system is completely online and includes

\section{Dovepress}

a very quick and fair peer-review system, which is all easy to use. Visit http://www.dovepress.com/testimonials.php to read real quotes from published authors. 